\title{
Bilateral Acute Iris Transillumination
}

Ilknur Tugal-Tutkun, MD; Sumru Onal, MD, FEBOphth; Aylin Garip, MD; Muhittin Taskapili, MD; Haluk Kazokoglu, MD; Sibel Kadayifcilar, MD; Philippe Kestelyn, MD

Objective: To describe a series of patients with bilateral acute iris transillumination, pigment dispersion, and sphincter paralysis.

Methods: We reviewed the medical records and clinical photographs of 26 patients seen at 5 centers in Turkey and Belgium between March 16, 2006, and July 6, 2010. Observation procedures included clinical examination, anterior segment color photography, gonioscopy, laser flare photometry, and pupillometry.

Results: All 26 patients (20 women and 6 men; mean [SD] age, 43.2 [10.5] years) had bilateral involvement. Twenty-three patients (88\%) had acute-onset disease with severe photophobia and red eyes. Nineteen patients (73\%) had a preceding flulike illness and used systemic antibiotics, including moxifloxacin. Diagnostic laboratory workup was unremarkable. There was pigment dis- charge into the anterior chamber, and flare was elevated in the absence of inflammatory cells. Most patients had severe diffuse transillumination of the iris and mydriatic distorted pupils. Pupillometry revealed a compromised reaction to light. The most serious complication was an intractable early rise in intraocular pressure. Gonioscopy revealed heavy pigment deposition in the trabecular meshwork. Although symptoms were relieved promptly by application of topical corticosteroid, the median duration of pigment dispersion was 5.25 months.

Conclusions: Bilateral acute iris transillumination with pigment dispersion and persistent mydriasis is a new clinical entity that is not an ocular adverse effect of oral moxifloxacin treatment, as previously suggested. The etiopathogenesis of this entity remains to be elucidated.

Arch Ophthalmol. 2011;129(10):1312-1319
Author Affiliations: Department of Ophthalmology, Istanbul Faculty of Medicine, Istanbul University, Istanbul, Turkey (Drs Tugal-Tutkun and Garip); Department of Ophthalmology, School of Medicine, Marmara University, Istanbul (Drs Onal and Kazokoglu); Department of Ophthalmology, Ludwig-Maximillian University, Munich, Germany (Dr Garip); Eye Clinic, Vakif Gureba Training and Research Hospital, Istanbul (Dr Taskapili); Department of Ophthalmology, School of Medicine, Hacettepe University, Ankara, Turkey (Dr Kadayifcilar); and Department of Ophthalmology, Ghent University Hospital, Ghent, Belgium (Dr Kestelyn).

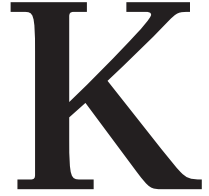

NOWN CAUSES OF ACQUIRED iris atrophy with or without transillumination of the iris include herpetic iridocyclitis, pigment dispersion syndrome (PDS), pseudoexfoliation syndrome, Fuchs uveitis syndrome, VogtKoyanagi-Harada disease, trauma, and acute angle-closure glaucoma. ${ }^{1-10}$ Pigment discharge into the anterior chamber is a diagnostic feature of PDS and may also occur in pseudoexfoliation syndrome. ${ }^{1,2}$ Pigment dispersion is also one of the diagnostic features of the recently described entity bilateral acute depigmentation of the iris (BADI). However, BADI is characterized by a nontransilluminating depigmentation of the iris stroma. ${ }^{11,12}$ More recently, an acquired bilateral diffuse iris transillumination with variable sphincter paralysis has been described as an ocular adverse effect of oral moxifloxacin treatment. ${ }^{13-15}$ We have seen patients with similar ocular findings with or without a history of moxifloxacin intake.

We herein describe the clinical features and course in 26 patients who developed bilateral acute iris transillumination (BAIT) associated with pigment showering and persistent mydriasis.

\section{METHODS}

Twenty-seven consecutive patients with BAIT were seen at 4 ophthalmology clinics in Turkey and 1 in Belgium between March 16, 2006, and July 6, 2010. One patient with concomitant Behçet disease was excluded from the study. We reviewed the medical and photographic records of the remaining 26 patients and used a standard data acquisition form at each center to gather retrospective data for this study. Informed consent of the patients was obtained for all procedures and treatments used. The study was approved by the ethics committee of Istanbul Faculty of Medicine, Istanbul University, Istanbul, Turkey, and was conducted according to the tenets of the Declaration of Helsinki.

At the initial visit, a detailed ocular and medical history was obtained from each patient, including onset of ocular complaints, previous systemic findings, and previous treatment(s). A complete ocular examination was conducted at each visit, including best-corrected visual acuity using a Snellen scale from 0.1 to 1.0, slitlamp biomicroscopy, tonometry, and indirect ophthalmoscopy. Gonioscopy was performed in all the patients. Corneal sensation was checked using a cotton yarn. Color photographs of the anterior segment were taken in each patient. We used the Vision Monitor WIN8000E (Metrovision, Perenchies, France) to perform pu- 
pillometry and a laser flare photometer (KOWA FC-2000; Kowa Co Ltd, Tokyo, Japan) to measure anterior chamber flare only in patients seen at the Uveitis Service of the Department of Ophthalmology, Istanbul Faculty of Medicine, Istanbul University. The pupil diameters were measured under photopic and scotopic conditions. Pupillometry was performed in age- and sexmatched control subjects for comparison with the retrospective data obtained from the study patients.

Diagnostic laboratory workup included erythrocyte sedimentation rate, complete blood cell count, and biochemistry. Serum IgG and IgM antibodies against herpes simplex virus types 1 and 2, varicella zoster virus, cytomegalovirus, and/or EpsteinBarr virus were measured in 10 patients. Patients were treated with topical corticosteroids when they had acute symptoms or ongoing high-grade pigment dispersion in the anterior chamber. Empirical oral acyclovir or valacyclovir therapy was given to the first 8 patients with pigment dispersion. In patients with an intraocular pressure (IOP) higher than $21 \mathrm{~mm} \mathrm{Hg}$, topical antiglaucomatous medications were used. If IOP exceeded 40 $\mathrm{mm} \mathrm{Hg}$, intravenous mannitol, $20 \%$, infusions were given.

The main outcome measures were demographic features, initial ocular and systemic symptoms, ocular clinical findings, and pupillometry and flare photometry measurements. In patients who had resolution of pigment dispersion during followup, time to resolution was also determined.

We used a commercially available statistical analysis program (SPSS, version 16.0 for Windows; SPSS Inc, Chicago, Illinois) for analysis of the data. The Mann-Whitney, Wilcoxon, and Kruskal-Wallis tests were used to test for differences between groups. The Dunn test was used as a multiple comparison post hoc test. Categorical data were analyzed by the $\chi^{2}$ test. $P<.05$ was considered significant.

\section{RESULTS}

Twenty patients were women and 6 were men. The mean (SD) patient age when first seen was 43.2 (10.5) years (median, 42 years; age range, 25-69 years). Seven patients were seen only once or had follow-up of less than 1 month. The remaining 19 patients had mean (SD) follow-up of 13.2 (12.2) months (median, 9.7 months; range, 1.5-43.0 months). All the patients had bilateral involvement. The demographic and clinical characteristics of the patients at the first visit are given in Table $\mathbf{1}$ and in eTable 1 and eTable 2 (http://www.archophthalmol.com).

\section{INITIAL OCULAR SYMPTOMS AND OCULAR HISTORY}

All the patients had an acute onset of ocular symptoms. Twenty-three patients (88\%) had or reported an acute onset of severe photophobia and red eyes. Three patients reported only red eyes. Both eyes were involved simultaneously; however, symptom severity could be asymmetrical. Seven patients were seen within 1 week of onset of ocular symptoms. The remaining 19 patients were referred with a diagnosis of iridocyclitis with unusual features. The median disease duration in the latter group was 2 months (range, 2 weeks to 14 months). All these patients had been treated with topical corticosteroids. Five patients reported systemic corticosteroid use, and 7 patients had been given oral antiviral medications. Twelve patients (63\%) had a history of IOP rise, bilaterally in 10. All these patients had been treated with

\begin{tabular}{|c|c|}
\hline Characteristic & Description \\
\hline Age, mean (SD) [range], y & $43.2(10.5)[25-69]$ \\
\hline \multicolumn{2}{|l|}{ Sex, No. (\%) } \\
\hline Female & $20(77)$ \\
\hline Male & $6(23)$ \\
\hline \multicolumn{2}{|l|}{ Initial symptoms, №. (\%) } \\
\hline Red eyes & $26(100)$ \\
\hline Photophobia & $23(88)$ \\
\hline Ocular pain & $10(38)$ \\
\hline Blurred vision & $7(27)$ \\
\hline \multicolumn{2}{|l|}{ Laterality, No. (\%) } \\
\hline Bilateral & $26(100)$ \\
\hline Unilateral & 0 \\
\hline \multicolumn{2}{|l|}{ Visual acuity, median (SEM) [range] } \\
\hline Right eye & $1.0(0.03)[0.3-1.0]$ \\
\hline Left eye & $1.0(0.03)[0.4-1.0]$ \\
\hline \multicolumn{2}{|l|}{ Patients; eyes with, №. (\%) } \\
\hline Conjunctival hyperemia & $7(27) ; 12(23)$ \\
\hline Pigment keratic precipitates & $12(46) ; 21(40)$ \\
\hline Circulating pigment in the $\mathrm{AC}$ & 23 (88); 45 (87) \\
\hline Transillumination & $26(100) ; 52(100)$ \\
\hline Bilateral diffuse & $21(81) ;-$ \\
\hline $\begin{array}{l}\text { Diffuse in } 1 \text { eye and moth-eaten in } \\
\text { the other eye }\end{array}$ & $4(15) ;-$ \\
\hline Bilateral moth-eaten & $1(4) ;-$ \\
\hline Mydriatic pupil with sphincter paralysis & $-; 46(88)$ \\
\hline Irregular distorted pupil & $20(77) ; 32(62)$ \\
\hline Posterior synechiae & $3(12) ; 4(8)$ \\
\hline \multicolumn{2}{|l|}{ Iris color, No. $(\%)$ of patients } \\
\hline Brown & $23(88)$ \\
\hline Blue & $2(8)$ \\
\hline Green & $1(4)$ \\
\hline \multicolumn{2}{|l|}{ IOP, mean (SD) [range], mm Hg } \\
\hline Right eye & $16.57(5.85)[9-37]$ \\
\hline Left eye & $18.80(7.82)[8-41]$ \\
\hline \multicolumn{2}{|l|}{$\begin{array}{l}\text { AC flare measured in } 18 \text { patients, mean } \\
\text { (SD) [range], ph/ms }\end{array}$} \\
\hline $\begin{array}{l}\text { (1) In } 10 \text { eyes with no pigment to } \\
0.5+\text { pigment in the } \mathrm{AC}\end{array}$ & $6.08(2.94)[3.50-13.00]$ \\
\hline $\begin{array}{l}\text { (2) In } 14 \text { eyes with } 1+\text { to } 2+ \\
\text { pigment in the AC }\end{array}$ & $12.08(9.19)[3.90-33.00]$ \\
\hline $\begin{array}{l}\text { (3) In } 12 \text { eyes with } 3+\text { to } 4+ \\
\text { pigment in the AC }\end{array}$ & 169.99 (151.77) [2.60-448.20] \\
\hline Kruskal-Wallis & 10.31 \\
\hline$P$ value & .005 \\
\hline Comparisons & $1<3^{a} ; 2<3^{b}$ \\
\hline
\end{tabular}

Abbreviations: AC, anterior chamber; IOP, intraocular pressure; ph/ms, photon count per millisecond; minus, negative.

a $P<.01$ by Dunn test.

b $P<.05$ by Dunn test.

topical antiglaucomatous medication(s) and 6 with concomitant oral acetazolamide. One patient had undergone trabeculectomy in 1 eye 7 months after onset of the disease. Another patient had required intravenous infusion of mannitol, 20\%, to control the IOP rise. Ocular history was otherwise unremarkable.

\section{SYSTEMIC SYMPTOMS AND MEDICAL HISTORY}

Nineteen patients (73\%) reported a flulike illness or upper respiratory tract infection preceding the onset of ocular symptoms. The mean (SD) interval between the on- 

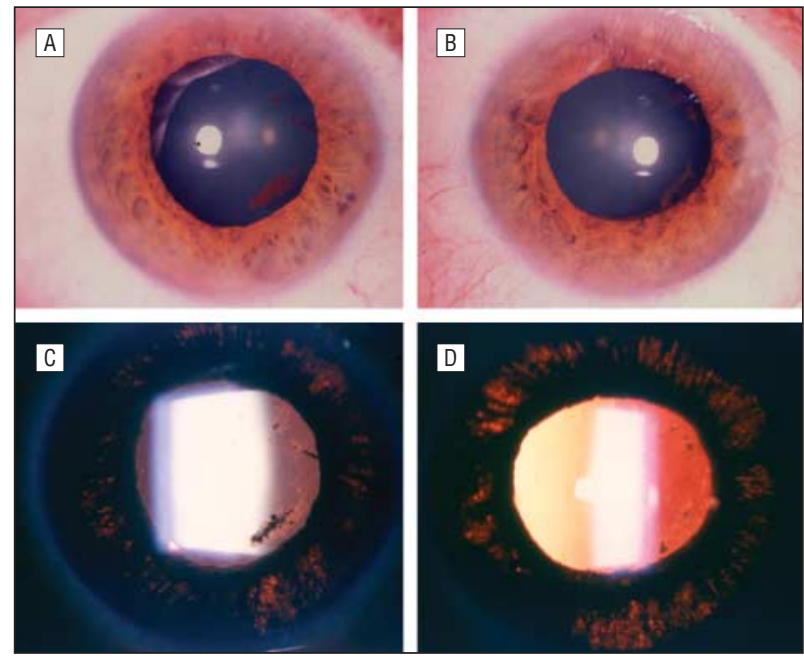

Figure 1. A 44-year-old woman (eCase1). The mydriatic pupils are poorly responsive to light in the right (A) and left (B) eyes. Severe diffuse iris transillumination is evident in the right (C) and left (D) eyes on retroillumination. Note the smeared iris pigment on the surface of the lens (A-D). The photographs were taken without pharmacologic dilation of the pupils.

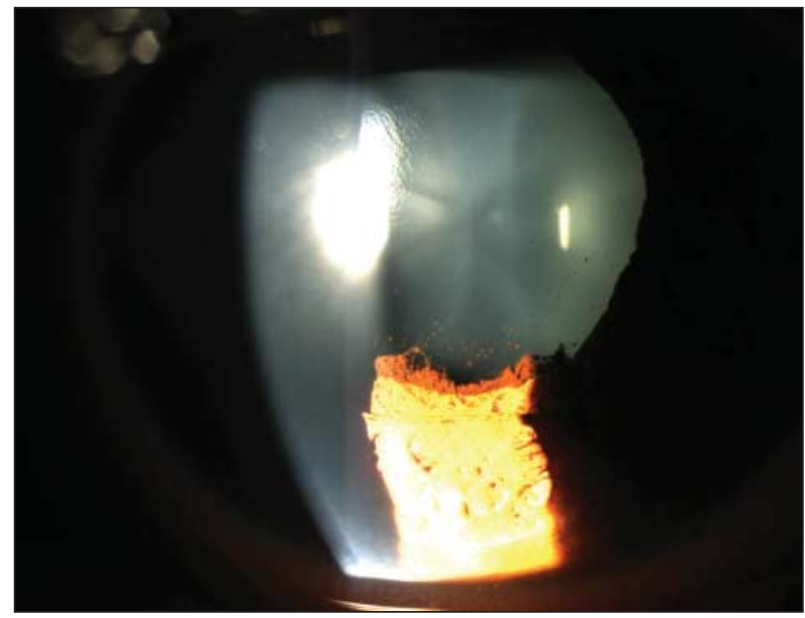

Figure 2. A 34-year-old man showing posterior synechiae with a broad base and a thick layer of iris pigment smeared on the surface of the lens. The pupil is mydriatic and unresponsive to light. The photograph was taken without pharmacologic dilation of the pupil.

set of systemic symptoms and the onset of ocular disease was 2.52 (1.46) weeks (median, 2 weeks; range, 1-6 weeks). All these patients had been treated with systemic antibiotics, including moxifloxacin in $9(35 \%)$, ampicillin-sulbactam in $2(8 \%)$, amoxicillin-clavulanate in $2(8 \%)$, and trimethoprim-sulphamethoxazole, cefixime, and penicillin V in 1 (4\%) each. Three patients could not recall the name of the antibiotic they had used. In 7 patients $(27 \%)$, the medical history was unremarkable.

\section{RESULTS OF THE LABORATORY WORKUP}

Routine laboratory results were within the reference ranges. Viral serologic analysis in 10 patients showed that the IgM antibodies were negative and the IgG antibodies were not elevated. In patients tested for IgG antibodies against herpes simplex virus type 1 and Epstein-Barr virus, seropositivity was $83 \%$ and $75 \%$, respectively. All patients tested for anti-varicella zoster virus and cytomegalovirus were found to have positive IgG antibodies. No patient was found to have IgG positivity against herpes simplex virus type 2 .

\section{INITIAL OCULAR FINDINGS}

Median visual acuity was $1.0 \mathrm{OU}$ (range, $0.3-1.0 \mathrm{OD}$ and 0.4-1.0 OS). Reduced visual acuity was due to amblyopia in 2 eyes. Another eye with visual acuity of 0.3 had a preretinal hemorrhage at the posterior pole that had occurred after trabeculectomy.

Conjunctival hyperemia was documented in the $7 \mathrm{pa}-$ tients (12 eyes) who were first seen within 1 week of the onset of ocular symptoms. Fine pigment precipitates on the corneal endothelium were recorded in 12 patients ( 21 eyes): in the form of Krukenberg spindle in 2 (4 eyes), diffusely scattered in 3 (6 eyes), and distributed in the lower half of the cornea in 7 ( 11 eyes). Inflammatory keratic precipitates were not seen.

None of the patients had inflammatory cells in the anterior chamber at the first visit or during follow-up. There was variable pigment dispersion in the anterior chamber in both eyes of 22 patients. Three patients who were first seen 4 months to 1 year after the onset of ocular symptoms had no circulating pigment in the anterior chamber but had diffuse transillumination of the iris and persistent mydriasis due to sphincter paralysis in both eyes. Another patient who was first seen on day 5 of the onset of ocular disease had 4+ pigment in the left eye only. However, pigment dispersion occurred in the other eye during follow-up but did not exceed $0.5+$. The iris of this patient exhibited diffuse transillumination in the left eye and only moth-eaten transillumination in the right eye.

Twenty-one patients (42 eyes) had severe diffuse transillumination of the iris and mydriatic pupils poorly responsive or unresponsive to light (Figure 1 and Appendix [eCase 1]). In 4 patients, there was asymmetrical involvement, with diffuse transillumination in 1 eye with a mydriatic pupil and less severe, moth-eaten transillumination without apparent mydriasis in the other eye. One patient had symmetrical bilateral moth-eaten transillumination with normal pupils. An irregular distorted pupil was also noted in 20 patients (32 eyes). Spiraling of the pupil was not apparent. Posterior synechiae were documented in 3 patients ( 4 eyes). The morphologic features of posterior synechiae were different from those of uveitic synechiae in that a thick layer of iris pigment seemed to be smeared on the surface of the lens and remained adherent with a broad base (Figure 2). In 10 patients (19 eyes), smeared iris pigment (Figure 1) or pigment dusting (Figure 3 and Appendix [eCase 2]) was seen on the surface of the lens. Scattered pigment particles were seen on the surface of the iris as well. One patient had unilateral mild posterior subcapsular lens opacity. The corneal sensation was intact, and the vitreous was clear in all the patients. The fundus was normal in all except 1 patient with preretinal hemorrhage at the posterior pole after trabeculectomy in 1 eye.

Mean IOP values are given in Table 1 . An IOP higher than $21 \mathrm{~mm} \mathrm{Hg}$ was measured in 8 patients (11 eyes). Nine patients were still taking topical antiglaucomatous medi- 
cation(s), and 4 of them were receiving concomitant oral acetazolamide therapy prescribed elsewhere. On gonioscopy, none of the eyes had an occludable angle. There was heavy pigment deposition especially in the inferior angle in all the patients. The amount of pigment deposition in the angle was asymmetrical in some patients.

Laser flare photometry was performed at the initial visit in 18 patients (36 eyes). Eyes with $3+$ to $4+$ pigment had significantly elevated mean laser flare photometry readings compared with those with none to $0.5+$ pigment $(P<.01)$ and those with $1+$ to $2+$ pigment $(P<.05)$.

\section{PUPILLOMETRY FINDINGS}

Pupillometry was performed in 15 patients and 20 controls (Table 2). Sex and mean age did not differ between the 2 groups. Under scotopic conditions, no significant difference was noted in pupil diameter between patients and controls $(P=.62$ for right eyes and $P=.85$ for left eyes); however, under photopic conditions, patients' mean pupil diameter was significantly larger $(P<.001$ for right and left eyes $)$. Patients had significantly reduced amounts of miosis. Pupillary reaction to near stimuli was also compromised. Accommodation was not measured in any patient; however, none of the patients required additional plus lenses for near vision.

\section{TREATMENT AND FOLLOW-UP}

Treatment and follow-up are summarized in eTable 2. Seven patients who were first seen within 1 week of the onset of ocular symptoms were treated with hourly topical corticosteroid application, which resulted in prompt relief of their symptoms. Seven patients who were referred 1 to 14 months after disease onset and had less than $2+$ pigment and low flare $(<15$ photon counts per millisecond $[\mathrm{ph} / \mathrm{ms}]$ ) were not given topical corticosteroids. Topical corticosteroid therapy prescribed elsewhere was maintained in 12 patients who were referred with a disease duration of 2 to 16 weeks and ongoing pigment dispersion. Four of them did not return for follow-up. Two of them with flare measurements exceeding $150 \mathrm{ph} / \mathrm{ms}$ were also given oral prednisolone $(0.5 \mathrm{mg} / \mathrm{kg} / \mathrm{d})$, which was tapered and discontinued within 6 weeks. The mean (SD) duration of topical corticosteroid treatment was 3.51 (2.00) months (median, 3 months; range, 1-8 months). In 11 patients, topical corticosteroid therapy was discontinued with slow tapering, and no relapse was seen. Only 1 patient had 2 relapses during tapering, which were controlled with an increased dose and successful discontinuation of treatment at 5 months. Mean (SD) follow-up after withdrawal of treatment in these 12 patients was 13.6 (12.4) months (median, 9.12 months; range, 1-39 months).

Mean (SD) time from onset of ocular symptoms to complete resolution of pigment dispersion in the anterior chamber was 7.30 (5.68) months (median, 5.25 months; range, $1-18$ months) in 14 patients (28 eyes). Resolution of pigment dispersion in the anterior chamber occurred simultaneously in both eyes in all except 2 patients. The mean (SD) flare was significantly reduced at the last visit (from 39.23 [73.44] to 5.18 [3.03] in right eyes, $P=.02$; and from 81.92 [132.66] to 4.52 [1.13] in left eyes, $P=.002$ ).

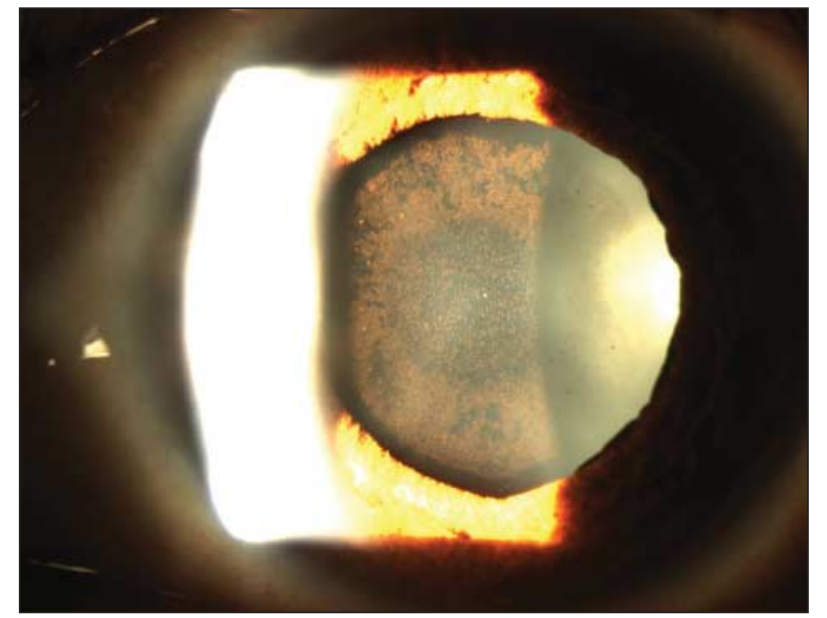

Figure 3. A 25-year-old woman showing pigment dusting on the surface of the lens (eCase2). The pupil is mydriatic and unresponsive to light. The photograph was taken without pharmacologic dilation of the pupil.

Two of the 7 patients who were first seen by us developed high IOP during follow-up. The IOP was raised within 1 week in both eyes of 1 patient and at 2 months in 1 eye of the other patient. None of the referred patients who did not have a history of IOP rise developed this complication during follow-up. Thus, 14 patients (54\%) had IOP rise during the disease course, and 10 received antiglaucomatous medication(s) during followup. The mean (SD) duration of topical antiglaucomatous therapy was 9.25 (8.16) months (median, 8.5 months; range, 1 month to 3 years). Seven patients required concomitant oral acetazolamide therapy, and 5 patients required intravenous infusion(s) of mannitol, 20\%. Two patients with high IOP despite maximum-tolerated medical therapy required bilateral trabeculectomy combined with mitomycin application 3 to 9 weeks after disease onset. Both of these patients had 4+ pigment in the anterior chamber before surgery, and a dense pigment accumulation occurred inside the bleb (Figure 4). The mean (SD) final IOP was 14.15 (2.87) $\mathrm{mm} \mathrm{Hg}$ (range, 10-20 $\mathrm{mm} \mathrm{Hg}$ ) in right eyes and 14.20 (3.07) $\mathrm{mm} \mathrm{Hg}$ (range, $8-21 \mathrm{~mm} \mathrm{Hg}$ ) in left eyes. Six patients were still taking topical antiglaucomatous medication(s) at the final visit. None of the patients developed glaucomatous optic disc changes or visual field defects.

Bilateral cataract developed in 7 patients. After resolution of pigment dispersion, 4 eyes underwent uneventful phacoemulsification and intraocular lens implantation. Visual acuity was well preserved. Median final visual acuity was $1.0 \mathrm{OU}$ (range, 0.4-1.0 OU). Visual acuity decreased to 0.4 in 1 eye due to cataract formation.

\section{COMMENT}

We described 26 patients with an unusual bilateral acute iris transillumination associated with symptomatic pigment showering after a flulike illness or an upper respiratory tract infection in most cases. Middle-aged women are more commonly affected. Despite the absence of inflammatory keratic precipitates or cells in the anterior chamber, pigment storm is associated with a flare rise, 
Table 2. Comparison of Demographic Features and Pupil Diameters in Patients and Control Subjects

\begin{tabular}{|c|c|c|c|c|c|c|}
\hline \multirow{2}{*}{$\frac{\text { Variable }}{\text { Demographic features }}$} & \multicolumn{2}{|c|}{$\begin{array}{c}\text { Patients } \\
(n=15)\end{array}$} & \multicolumn{2}{|c|}{$\begin{array}{l}\text { Control Subjects } \\
\qquad(n=20)\end{array}$} & \multicolumn{2}{|c|}{$P$ Value $^{\mathrm{a}}$} \\
\hline & \multirow{2}{*}{\multicolumn{2}{|c|}{$10 / 5$}} & & & & \\
\hline Sex, F/M, No. & & & \multicolumn{2}{|c|}{$14 / 6$} & \multicolumn{2}{|c|}{$.83^{b}$} \\
\hline Age, mean (SD) [range], y & \multicolumn{2}{|c|}{$43.0(12.4)$ [25 to 69] } & \multicolumn{2}{|c|}{$40.1(8.8)[26$ to 58$]$} & \multicolumn{2}{|c|}{.52} \\
\hline Pupil diameter, mm & OD & OS & OD & OS & OD & OS \\
\hline \multicolumn{7}{|l|}{ Photopic } \\
\hline Mean (SD) & $3.84(0.97)$ & $4.12(1.08)$ & $2.41(0.21)$ & $2.29(0.13) 7$ & \multirow{3}{*}{$<.001$} & \multirow{3}{*}{$<.001$} \\
\hline Median (SEM) & $3.80(0.25)$ & $4.20(0.27)$ & $2.35(0.04)$ & $2.25(0.03)$ & & \\
\hline Range & 2.4 to 5.6 & 2.3 to 5.4 & 2.2 to 3.1 & 2.2 to 2.7 & & \\
\hline \multicolumn{7}{|l|}{ Scotopic } \\
\hline Mean (SD) & $5.04(0.87)$ & $4.89(0.98)$ & $5.19(0.77)$ & $5.05(0.62) 7$ & \multirow{3}{*}{.62} & \multirow{3}{*}{.85} \\
\hline Median (SEM) & $4.90(0.22)$ & $5.20(0.25)$ & $5.10(0.17)$ & $5.15(0.14)$ & & \\
\hline Range & 3.3 to 6.4 & 2.6 to 6.4 & 3.9 to 6.6 & 3.9 to 6.2 & & \\
\hline \multicolumn{7}{|l|}{ Miosis, mm } \\
\hline Mean (SD) & $1.20(1.24)$ & $0.77(0.90)$ & $2.78(0.69)$ & $2.75(0.58) 7$ & \multirow{3}{*}{$<.001$} & \multirow{3}{*}{$<.001$} \\
\hline Median (SEM) & $0.90(0.32)$ & $0.40(0.23)$ & $2.80(0.15)$ & $2.90(0.12)$ & & \\
\hline Range & -0.20 to 3.9 & -0.6 to 2.7 & 1.5 to 4.0 & 1.5 to 3.5 & & \\
\hline
\end{tabular}

a Mann-Whitney test.

${ }^{b} \chi^{2}=.04$.
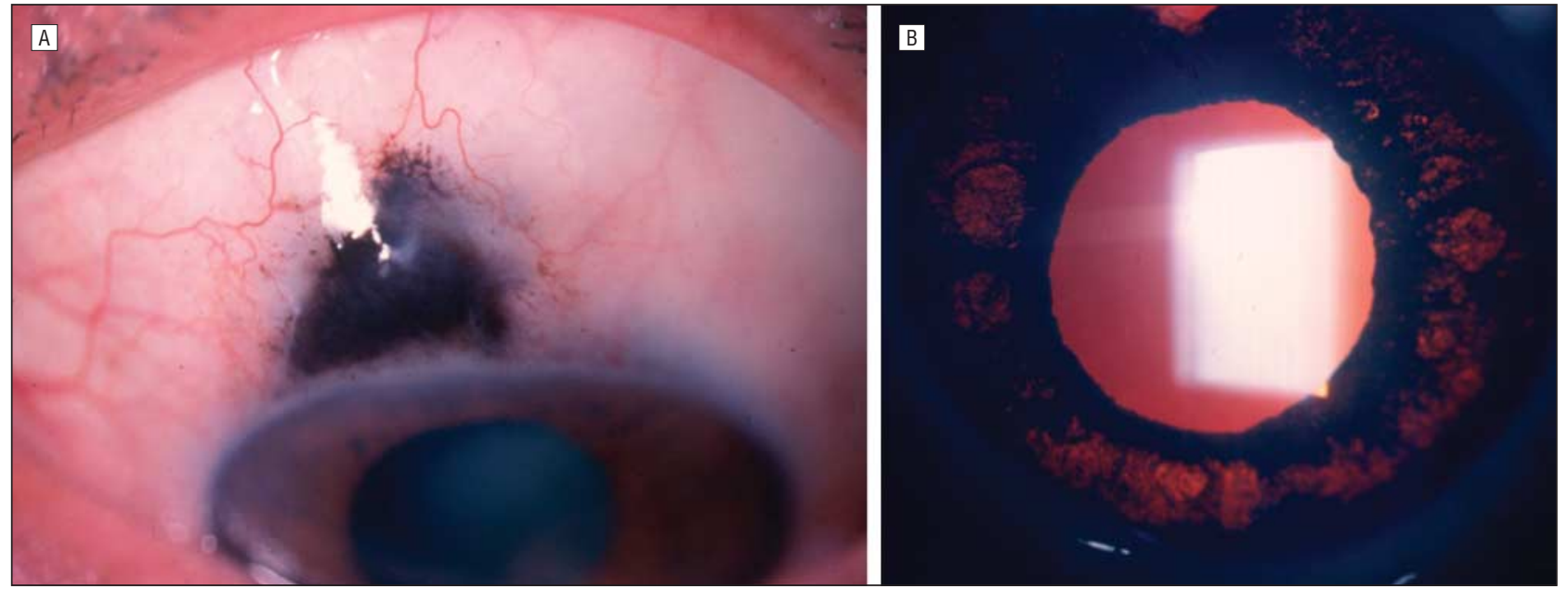

Figure 4. A 53-year-old man who underwent left trabeculectomy combined with mitomycin application 9 weeks after disease onset because of high intraocular pressure despite maximum-tolerated medical therapy. A, Dense pigment accumulation occurred inside the bleb 3 months after surgery. B, Severe diffuse iris transillumination and a mydriatic pupil unresponsive to light are also evident. A peripheral iridectomy is discernable at the 12-0'clock position. The photographs were taken without pharmacologic dilation of the pupil.

and patients may be misdiagnosed as having acute bilateral iridocyclitis. Clinical findings that challenge conventional diagnosis include bilateral severe transillumination of the iris, pigment dispersion in the anterior chamber, and a mydriatic pupil that is unresponsive or poorly responsive to light due to variable sphincter paralysis. Symptoms are rapidly responsive to topical corticosteroid therapy; however, pigment dispersion may last months and even up to more than 1 year. An early rise in IOP is a common complication and can be refractory to treatment. The etiology remains unknown.

There are recent reports on the occurrence of acute pigment dispersion and iris transillumination after oral moxifloxacin treatment. Bilateral abundant pigment dispersion has been reported as a complication of moxifloxacin used for the treatment of pneumonia. ${ }^{13}$ More recently, Wefers Bettink-Remeijer et al ${ }^{14}$ described 5 patients who had an acute onset of photophobia and pain fol- lowed by bilateral diffuse iris transillumination with variable sphincter paralysis and concluded that this was an ocular adverse effect of oral moxifloxacin use. Most patients in the present cohort had a preceding flulike illness or respiratory tract infection before the onset of ocular symptoms; although only approximately $35 \%$ reported moxifloxacin intake, $40 \%$ were exposed to other antibiotics. Therefore, we believe that the clinical picture described herein may represent a distinct condition probably triggered by a viral infection. Theoretically, such an ocular adverse effect would also be expected to occur with the topical application of moxifloxacin, which has been shown to have efficient ocular penetration. ${ }^{16}$ To our knowledge, there is no such reported ocular adverse effect of topical moxifloxacin treatment.

The differential diagnosis of BAIT is summarized in Table 3. Pigment dispersion syndrome is the most difficult to differentiate from the entity described herein. Se- 
Table 3. Differential Diagnosis of BAIT

\begin{tabular}{|c|c|c|c|c|c|c|}
\hline Characteristic & $\begin{array}{c}\text { Herpetic } \\
\text { Iridocyclitis }\end{array}$ & FUS $^{5,6}$ & PXF$^{2}$ & BADI $^{11,12}$ & PDS $^{1,17-19}$ & BAIT \\
\hline Sex & No predilection & No predilection & Commonly female & $\begin{array}{l}\text { Female predominance } \\
(2.7: 1)\end{array}$ & Mostly male & $\begin{array}{l}\text { Female } \\
\text { predominance } \\
(3.3: 1)\end{array}$ \\
\hline Symptoms at onset & $\begin{array}{l}\text { Symptomatic, with red } \\
\text { eyes, ocular pain, } \\
\text { and photophobia }\end{array}$ & Asymptomatic & Asymptomatic & $\begin{array}{l}\text { Severe photophobia } \\
\text { and red eyes }\end{array}$ & $\begin{array}{l}\text { Usually } \\
\text { asymptomatic; } \\
\text { occasionally } \\
\text { headache, blurred } \\
\text { vision, and halos } \\
\text { around light during } \\
\text { pigment showering }\end{array}$ & $\begin{array}{l}\text { Severe photophobia } \\
\text { and red eyes }\end{array}$ \\
\hline Laterality & Typically unilateral & Typically unilateral & $\begin{array}{l}\text { Bilateral } \\
\text { asymmetrical }\end{array}$ & Bilateral symmetrical & $\begin{array}{l}\text { Bilateral, mostly } \\
\text { symmetrical }\end{array}$ & $\begin{array}{l}\text { Bilateral, mostly } \\
\text { symmetrical }\end{array}$ \\
\hline Keratic precipitates & Inflammatory & $\begin{array}{l}\text { Inflammatory, diffuse } \\
\text { stellate, and } \\
\text { medium sized }\end{array}$ & Pigment & Pigment & Pigment & Pigment \\
\hline Krukenberg spindle & None & None & None & Sometimes present & Present & Sometimes present \\
\hline $\begin{array}{l}\text { Pigment particles in } \\
\text { the } A C\end{array}$ & None & None & $\begin{array}{c}\text { Sometimes } \\
\text { present }\end{array}$ & Present & Present & Present \\
\hline $\begin{array}{l}\text { Inflammatory cells } \\
\text { in the } A C\end{array}$ & $\begin{array}{l}\text { Present during } \\
\text { exacerbations }\end{array}$ & Chronic, low grade & None & None & None & None \\
\hline $\begin{array}{l}\text { Iris } \\
\quad \text { transillumination }\end{array}$ & Patchy or sectoral & Rarely peripupillary & Peripupillary & None & $\begin{array}{l}\text { Midperipheral } \\
\text { spokelike }\end{array}$ & Diffuse \\
\hline $\begin{array}{l}\text { Change in the iris } \\
\text { configuration }\end{array}$ & None & None & None & None & Posterior bowing & None \\
\hline $\begin{array}{l}\text { Iris stromal } \\
\text { changes }\end{array}$ & $\begin{array}{l}\text { Patchy or sectoral } \\
\text { stromal atrophy }\end{array}$ & $\begin{array}{l}\text { Diffuse stromal } \\
\text { atrophy with } \\
\text { blunting of iris } \\
\text { crypts with or } \\
\text { without } \\
\text { heterochromia }\end{array}$ & None & $\begin{array}{l}\text { Bilateral symmetrical } \\
\text { geographic or diffuse } \\
\text { depigmentation and } \\
\text { granularity with } \\
\text { distinct margins }\end{array}$ & None & None \\
\hline Pupillary changes & $\begin{array}{l}\text { Usually present, } \\
\text { irregular distorted } \\
\text { pupil with spiraling }\end{array}$ & $\begin{array}{l}\text { Rarely anisocoria, } \\
\text { with larger pupil on } \\
\text { the affected side }\end{array}$ & None & None & $\begin{array}{l}\text { Anisocoria in } \\
\text { asymmetrical } \\
\text { cases, with } \\
\text { preserved light and } \\
\text { near response }\end{array}$ & $\begin{array}{l}\text { Present; usually } \\
\text { symmetrical, } \\
\text { dilated atonic pupil } \\
\text { with compromised } \\
\text { reaction to light } \\
\text { and near stimuli }\end{array}$ \\
\hline IOP rise & $\begin{array}{l}\text { Acute and transient } \\
\text { during exacerbations, } \\
\text { related to trabeculitis }\end{array}$ & $\begin{array}{l}\text { Frequent } \\
\text { complication } \\
\text { developing over } \\
\text { years }\end{array}$ & $\begin{array}{l}\text { Frequent } \\
\text { complication } \\
\text { developing over } \\
\text { years }\end{array}$ & Uncommon, transient & $\begin{array}{l}\text { Frequent complication } \\
\text { developing over } \\
\text { years }\end{array}$ & $\begin{array}{l}\text { Early complication, } \\
\text { resistant }\end{array}$ \\
\hline Gonioscopy & Open angle & $\begin{array}{l}\text { Open angle, new } \\
\text { vessels, } \\
\text { occasionally } \\
\text { goniosynechiae }\end{array}$ & $\begin{array}{l}\text { Pseudoexfoliation } \\
\text { material }\end{array}$ & Pigment deposition & Pigment deposition & Pigment deposition \\
\hline
\end{tabular}

Abbreviations: AC, anterior chamber; BADI, bilateral acute depigmentation of the iris; BAIT, bilateral acute iris transillumination; FUS, Fuchs uveitis syndrome; IOP, intraocular pressure; PDS, pigment dispersion syndrome; PXF, pseudoexfoliation syndrome.

vere photophobia and markedly red eyes, as seen in the present series, are not characteristic of PDS. Patients described herein developed severe diffuse iris transillumination at a single episode and did not have a midperipheral radial spokelike pattern, which typically develops over a chronic progressive course in PDS. Ocular hypertension or pigmentary glaucoma develops over years in PDS, ${ }^{17}$ whereas the IOP rise occurred within weeks to months in the present series. Pupillary reactions to light and near stimuli are not affected in PDS. ${ }^{18,19}$ Compromised pupillary constriction to light was thought to be related to variable amounts of sphincter paralysis in the present patients. Posterior bowing of the iris is a characteristic feature of PDS. ${ }^{1}$ Willermain et $\mathrm{al}^{15}$ described a patient with bilateral symptomatic acute iris transillumination, pigment dispersion, and severe IOP rise after moxifloxacin use. Go- nioscopy revealed heavy pigment deposition in the iridocorneal angle, and anterior segment optical coherence tomography showed iris concavity in their patient. ${ }^{15}$ Because iris concavity is a typical finding in PDS, their patient probably had PDS and an acute elevation in IOP due to the use of subconjunctival corticosteroids. Although we did not perform anterior segment optical coherence tomography or ultrasound biomicroscopy, we do not have any clinical observation of iris concavity or posterior bowing in any patient. This finding has not been reported by other researchers either. ${ }^{13,14}$

Pigment dispersion is also one of the diagnostic features of the recently described entity BADI, which is characterized by nontransilluminating depigmentation of the iris stroma and pigment discharge into the anterior chamber. Common features of BADI and the condition de- 
scribed herein include an acute onset of severe photophobia and red eyes after a flulike syndrome, pigment discharge into the anterior chamber, and exclusive involvement of the iris. Oral antibiotic drug use was reported in $38.5 \%$ of patients with BADI, including moxifloxacin use in $30.7 \%$ and amoxicillin-clavulanate use in $7.7 \% .{ }^{12}$ Even if BAIT may be a more severe form of BADI and both conditions have a common etiology, the pigment discharge seems to be only from the iris pigment epithelium in the former and from the iris stroma in the latter. The most important differentiating feature between the 2 entities is that the pupil is not affected in BADI and a symmetrical geographic or diffuse depigmentation of the iris stroma causes a change in iris stromal texture and color without any transillumination defect, ${ }^{11,12}$ whereas patients described herein typically had atonic dilated pupils and diffuse iris transillumination without any visible change to the iris stroma. Furthermore, BADI has a more benign course with a shorter duration of pigment discharge, a lower incidence of IOP rise that is only transient, and reversibility of iris changes reported at least in some patients. ${ }^{11,12}$ Heavy pigment deposition in the trabecular meshwork was a consistent finding in the present series and explained the early severe IOP rise that could occur as early as 1 week and the need for trabeculectomy as early as 3 weeks after onset. On the other hand, a corticosteroid-induced IOP rise cannot be excluded in patients who developed this complication later on.

The present patients clearly differed from those with pseudoexfoliation syndrome, Fuchs uveitis syndrome, and herpetic anterior uveitis. Sectoral iris atrophy with chronic refractory glaucoma may rarely be seen in immunocompetent patients with cytomegalovirus anterior uveitis. ${ }^{20-22}$ Aqueous humor analysis for local antibody production or demonstration of viral DNA is needed for a definite diagnosis of viral etiology. Diffuse iris atrophy has been reported in 50\% and elevated IOP in 100\% of eyes diagnosed as having cytomegalovirus anterior uveitis. ${ }^{20}$ However, in those eyes, diffuse iris transillumination and sphincter paralysis have not been described. ${ }^{20}$ Anterior chamber tap was reported to be negative for herpes viruses in 5 of the 6 cases previously reported in the literature with findings similar to the present series, and the herpes virus genome was found in only 1 patient, who had a history of uveitis. ${ }^{14,15}$ The causative agent of the preceding systemic illness is not known in any of the present patients. With the emergence of new respiratory viruses, new disease entities may develop, and conjunctiva may not be the only ocular tissue affected by these infections. $.^{23} \mathrm{Al}-$ though we presume that the entity described herein might be related to a systemic viral infection, the pathogenesis of iris involvement remains elusive. Because we could not perform iris angiography, we could not exclude iris ischemia as a possible cause of irreversible damage to the iris pigment layer and the pupillary sphincter. Ischemic iris changes have been reported to occur in $52.5 \%$ of cases after an episode of angle-closure glaucoma. ${ }^{10}$ Although an iris ischemia may be caused by an episode of angleclosure glaucoma precipitated, for example, by the use of vasoconstrictors during a flulike illness, gonioscopy did not reveal occludable angles in any eye in this series. Moreover, an elevated IOP was not reported at the onset of the disease in any of the referral cases, and the IOP was low to normal in patients who were seen first by us.

This study is limited by its retrospective nature, lack of intraocular fluid analysis, unavailability of iris angiography, and variable treatment and follow-up. We regret that iris specimens obtained by iridectomy in patients who underwent trabeculectomy were not sent to the laboratory for histologic analysis, culture, and other studies that could have shed light on the etiopathogenesis of this condition.

In conclusion, we described an unusual condition with symptoms masquerading as acute iridocyclitis and ocular findings bearing similarities to PDS. An acute onset of severe photophobia and red eyes after a flulike illness or upper respiratory tract infection is the typical presentation. Bilateral severe iris transillumination, an abundant pigment discharge into the anterior chamber, and atonic and distorted pupils are the constellation of findings distinct for this condition. This may be a new entity or may represent an expanded spectrum of BADI. Even if the latter is true, prompt recognition of this condition is essential because of the high risk of early severe IOP rise.

Submitted for Publication: December 10, 2010; final revision received March 21, 2011; accepted March 24, 2011. Correspondence: Ilknur Tugal-Tutkun, Istanbul Tip Fakultesi, Goz Hastaliklari AD, 34390 Capa, Istanbul, Turkey (itutkun@yahoo.com).

Financial Disclosure: None reported.

Online-Only Materials: The Appendix and eTables are available at http://www.archophthalmol.com.

\section{REFERENCES}

1. Niyadurupola N, Broadway DC. Pigment dispersion syndrome and pigmentary glaucoma: a major review. Clin Experiment Ophthalmol. 2008;36(9):868-882.

2. Ritch R, Schlötzer-Schrehardt U. Exfoliation syndrome. Surv Ophthalmol. 2001; 45(4):265-315.

3. Van der Lelij A, Ooijman FM, Kijlstra A, Rothova A. Anterior uveitis with sectoral iris atrophy in the absence of keratitis: a distinct clinical entity among herpetic eye diseases. Ophthalmology. 2000;107(6):1164-1170.

4. Siverio Júnior CD, Imai Y, Cunningham ET Jr. Diagnosis and management of herpetic anterior uveitis. Int Ophthalmol Clin. 2002;42(1):43-48.

5. Mohamed Q, Zamir E. Update on Fuchs' uveitis syndrome. Curr Opin Ophthalmol. 2005;16(6):356-363.

6. Tugal-Tutkun I, Güney-Tefekli E, Kamaci-Duman F, Corum I. A cross-sectional and longitudinal study of Fuchs uveitis syndrome in Turkish patients. Am J Ophthalmol. 2009;148(4):510-515, e1.

7. Attia S, Zaouali S, Bettaieb A, Yahia SB, Khairallah M. Peripheral iris depigmentation and ocular hypotony: result of the natural course of non-treated VogtKoyanagi-Harada (VKH) disease. Int Ophthalmol. 2007;27(2-3):221-222.

8. Suhler EB, Buggage RR, Nussenblatt RB, Neumann R. Symmetric peripheral iris depigmentation in Vogt-Koyanagi-Harada syndrome. Arch Ophthalmol. 2002 120(8):1104-1105.

9. Canavan YM, Archer DB. Anterior segment consequences of blunt ocular injury. Br J Ophthalmol. 1982;66(9):549-555.

10. Loon SC, Chew PT, Oen FT, et al. Iris ischaemic changes and visual outcome after acute primary angle closure. Clin Experiment Ophthalmol. 2005;33(5): 473-477.

11. Tugal-Tutkun I, Urgancioglu M. Bilateral acute depigmentation of the iris. Graefes Arch Clin Exp Ophthalmol. 2006;244(6):742-746.

12. Tugal-Tutkun I, Araz B, Taskapili M, et al. Bilateral acute depigmentation of the iris: report of 26 new cases and four-year follow-up of two patients. Ophthalmology. 2009;116(8):1552-1557, 1557.e1.

13. Bringas Calvo R, Iglesias Cortiñas D. Acute and bilateral uveitis secondary to moxifloxacin [in Spanish]. Arch Soc Esp Oftalmol. 2004;79(7):357-359.

$\overline{\text { ARCH OPHTHALMOL/VOL } 129 \text { (NO. 10), OCT } 2011 \text { WWW.ARCHOPHTHALMOL.COM }}$ 
14. Wefers Bettink-Remeijer M, Brouwers K, van Langenhove L, et al. Uveitis-like syndrome and iris transillumination after the use of oral moxifloxacin. Eye (Lond). 2009;23(12):2260-2262.

15. Willermain F, Deflorenne C, Bouffioux C, Janssens X, Koch P, Caspers L. Uveitislike syndrome and iris transillumination after the use of oral moxifloxacin. Eye (Lond). 2010;24(8):1419-1420.

16. Robertson SM, Curtis MA, Schlech BA, et al. Ocular pharmacokinetics of moxifloxacin after topical treatment of animals and humans. Surv Ophthalmol. 2005; 50(suppl 1):S32-S45.

17. Siddiqui Y, Ten Hulzen RD, Cameron JD, Hodge DO, Johnson DH. What is the risk of developing pigmentary glaucoma from pigment dispersion syndrome? Am J Ophthalmol. 2003;135(6):794-799.

18. Feibel RM, Perlmutter JC. Anisocoria in the pigmentary dispersion syndrome. Am J Ophthalmol. 1990;110(6):657-660.
19. Feibel RM. Anisocoria in the pigmentary dispersion syndrome: further cases. J Glaucoma. 1993;2(1):37-38.

20. Chee SP, Bacsal K, Jap A, Se-Thoe SY, Cheng CL, Tan BH. Clinical features of cytomegalovirus anterior uveitis in immunocompetent patients. Am J Ophthalmol. 2008;145(5):834-840.

21. Markomichelakis NN, Canakis C, Zafirakis P, Marakis T, Mallias I, Theodossiadis $\mathrm{G}$. Cytomegalovirus as a cause of anterior uveitis with sectoral iris atrophy. Ophthalmology. 2002;109(5):879-882.

22. de Schryver I, Rozenberg F, Cassoux N, et al. Diagnosis and treatment of cytomegalovirus iridocyclitis without retinal necrosis. Br J Ophthalmol. 2006;90 (7):852-855.

23. Fouchier RA, Rimmelzwaan GF, Kuiken T, Osterhaus AD. Newer respiratory virus infections: human metapneumovirus, avian influenza virus, and human coronaviruses. Curr Opin Infect Dis. 2005;18(2):141-146.

\section{From the Archives of the ARCHIVES}

T aher (348, On the treatment and prognosis of primary glaucoma). The author aims at a cystoid scar. He draws out a large loop of iris and allows the wound to heal before he excises the iris. . . .

In many cases an iris encleisis, even if it does not lead to septic infection, provides a bridge along which endothelial cells proliferate till they reach the iridic angle which they block and cause a glaucoma which is beyond treatment. Lagrange's and Herbert's methods are far preferable in every way. Most surgeons carefully avoid if possible any iris encleisis, which is recognized to be a potent cause of failure. The author only recommends his operation for chronic cases.

Source: Coburn EB. Report of the proceedings of the section on ophthalmology of the New York Academy of Medicine. Arch Ophthalmol. 1911;40:311. 